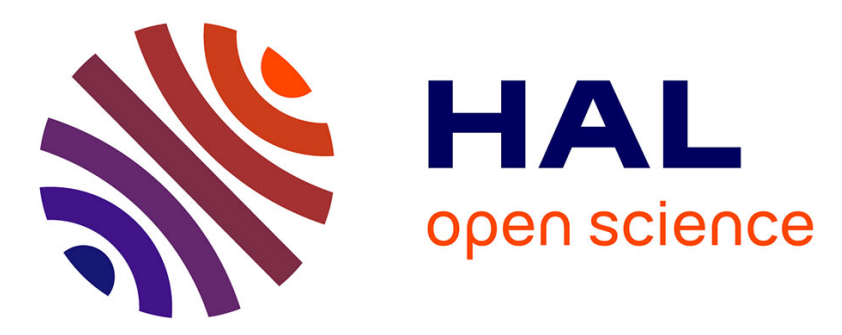

\title{
Ruthenium-Catalyzed C-H Bond Heteroarylation of Triazoles Enabled by a Deconvolution Strategy
}

Rafael Gramage-Doria, Thierry Roisnel

\section{To cite this version:}

Rafael Gramage-Doria, Thierry Roisnel. Ruthenium-Catalyzed C-H Bond Heteroarylation of Triazoles Enabled by a Deconvolution Strategy. European Journal of Organic Chemistry, 2018, 2018 (44), pp.6083-6087. 10.1002/ejoc.201800843 . hal-01897465

HAL Id: hal-01897465

https://hal-univ-rennes1.archives-ouvertes.fr/hal-01897465

Submitted on 8 Nov 2018

HAL is a multi-disciplinary open access archive for the deposit and dissemination of scientific research documents, whether they are published or not. The documents may come from teaching and research institutions in France or abroad, or from public or private research centers.
L'archive ouverte pluridisciplinaire HAL, est destinée au dépôt et à la diffusion de documents scientifiques de niveau recherche, publiés ou non, émanant des établissements d'enseignement et de recherche français ou étrangers, des laboratoires publics ou privés. 


\section{Ruthenium-Catalyzed C-H Bond Heteroarylation of Triazoles Enabled by a Deconvolution Strategy}

\author{
Rafael Gramage-Doria, ${ }^{[a]}$ and Thierry Roisnel ${ }^{[a]}$
}

\begin{abstract}
Reaction optimization for $\mathrm{C}-\mathrm{H}$ bond functionalization reactions with transition metal catalysts is traditionally based on long and tedious screening of multiple conditions. In this contribution we have applied a deconvolution strategy to identify reaction conditions suitable for the $\mathrm{C}-\mathrm{H}$ bond heteroarylation of 1,2,3-triazoles with a ruthenium catalyst by performing only 18 experiments with mixtures of reagents instead of the theoretically 576 experiments that should have been considered individually. The activation and functionalization takes place at the ortho position of the phenyl ring attached to the 1,2,3-triazole directing group as confirmed by $\mathrm{X}$-ray crystallographic studies. The bis- vs mono-heteroarylation was controlled by tuning the stoichiometry of the reagents. Such methodology was also applicable to aryl bromide coupling partners bearing ortho- and meta-substituents.
\end{abstract}

\section{Introduction}

1,2,3-Triazoles have become particularly relevant in the last decades due to the ease, versatile and modular synthesis that provides the copper(I)-catalyzed Huisgen 1,3-dipolar cycloaddition between terminal alkynes and azides. ${ }^{[1]}$ This unprecedented chemical space enabled 1,2,3-triazoles to find a large number of applications ranging from materials sciences to biology. ${ }^{[2]}$ However, the synthesis of the 1,2,3-triazole core containing bulky substituents at close proximity is rather challenging due to important steric restrictions and it has been met with success in limited cases with non-catalyzed synthetic sequences. ${ }^{[3]}$ On the other hand, bulky 1,2,3-triazoles appear as a promising class of compounds for medical applications ${ }^{[4]}$ as well as organocatalysts when transformed into its corresponding imidazolium salts. ${ }^{[5]}$

In this context, the introduction of bulky substituents once the triazole is formed has been regarded as a useful approach. This can be targeted by $\mathrm{C}-\mathrm{H}$ bond functionalization reactions employing transition metal catalysts with the triazole serving as a directing group. Several examples have shown their viability, although most of them are based on expensive and scarce rhodium and palladium catalysts. ${ }^{[6]}$ Interestingly, ruthenium complexes, which are significantly more available and less sensitive to air and moisture, were found to behave as efficient catalysts for the $\mathrm{C}-\mathrm{H}$ bond functionalization of 1,2,3-triazoles. ${ }^{[7,8]}$ For instance, Ackermann and co-workers reported ruthenium catalysts able to perform arylation and alkenylation reactions on the $\mathrm{C}-\mathrm{H}$ bond of the phenyl ring attached to the 1,2,3-triazole (Scheme 1, left). ${ }^{[7]}$ Similarly, Liu and co-workers employed ruthenium catalysts for the alkenylation of triazoles using alkynes and alkenes as coupling partners. ${ }^{[8 a]}$ Recently, Chatani and co-workers have reported on ruthenium(0)-catalyzed ortho-

[a] Univ Rennes, CNRS, ISCR-UMR 6226, F-35000 Rennes, France E-mail: rafael.gramage-doria@univ-rennes1.fr

Supporting information and ORCID(s) from the author(s) for this article are available on the WWW under https://doi.org./XXX
$\mathrm{C}-\mathrm{H}$ bond carbonylations using 1,2,3-triazoles as directing groups. ${ }^{[8 b]}$ Besides its obvious relevance, what all these studies have in common is the lack of examples enabling the introduction of heteroaromatic fragments at close proximity of the 1,2,3-triazole ring. ${ }^{[6-8]}$ This could be explained by the fact that the catalyst is not enough reactive and it can follow inhibition/deactivation by over-coordination to the heteroaromatic motifs. Furthermore, the identification of optimal reaction conditions for $\mathrm{C}-\mathrm{H}$ bond functionalization reactions is mainly based on trial and error screening of all the individual possibilities. ${ }^{[9]}$ At this stage, we wondered whether it could be possible to apply deconvolution strategies for rapid identification of suitable reaction conditions for the ruthenium-catalyzed heteroarylation of 1,2,3-triazoles. Deconvolution strategies have been applied in the last years involving different transition metalcatalyzed reactions but not for the case of ruthenium catalysis so far. ${ }^{[10]}$ By performing reactions with mixture of reagents, deconvolution strategies enable a more efficient discovery of optimal reaction conditions with less experiments than traditional error and screening approach. Herein, we disclose the application of this strategy to ruthenium-catalyzed $\mathrm{C}-\mathrm{H}$ bond heteroarylation reactions with 1,2,3-triazoles as directing groups (Scheme 1, right).

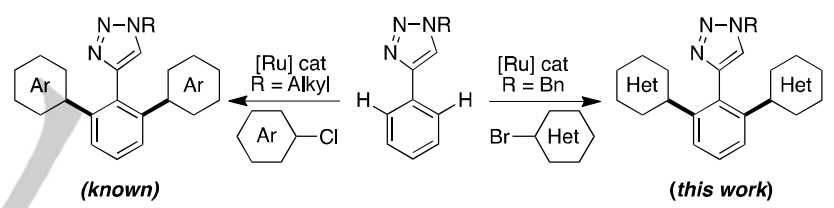

Scheme 1. Ruthenium-catalyzed C-H bond arylation (left) vs heteroarylation (right) of 1,2,3-triazoles.

\section{Results and Discussion}

First, we focused on the reaction of benchmark 1,2,3-triazole 1 with 4-bromopyridine as coupling partner (Figure 1). Then, we defined which parameters of the catalysis were fixed and which reagents could be used according to precedents from the literature. ${ }^{[7-9]}$ As solvents, we decided to screen water, toluene and $\mathrm{N}$-methyl-2-pyrrolidone (NMP) at $150{ }^{\circ} \mathrm{C}$ during 48 hours; and as ruthenium pre-catalysts, $\mathrm{RuCl}_{3} \cdot \mathrm{xH}_{2} \mathrm{O}$ (Ru1), $\left[\mathrm{RuCl}_{2}(p-\right.$ cymene) $]_{2}$ (Ru2) and $\mathrm{Ru}_{3}(\mathrm{CO})_{12}$ (Ru3) were chosen (Figure 1). As co-catalysts we considered up to eight carboxylate salts (C1C8) and the same number of bases (B1-B8) (Figure 1). Initially, we performed three experiments in which all the reagents (ruthenium complexes Ru1-Ru3, carboxylate salts C1-C8 and bases B1-B8) were mixed together with the three solvents respectively (step 1). Only the reaction conducted with NMP lead to some conversion (10\%) and consequently, it was selected as the solvent of choice for the next experiments. Then, three reactions were carried out in which each one contained a single ruthenium complex (step 2), indicating that $\left[\mathrm{RuCl}_{2}(p-\right.$ cymene) $]_{2}$ (was the most efficient catalysts under these reaction 
conditions (12\% conversion). Next, we decided to divide in two groups the carboxylate salts (C1-C4 and $\mathbf{C 5}-\mathbf{C 8})$ as well as the bases (B1-B4 and B5-B8). Four reactions were carried out combining the two groups of carboxylate salts and the two groups of bases, respectively, with the already selected $\left[\mathrm{RuCl}_{2} \text { (p-cymene) }\right]_{2}$ complex and NMP as solvent (step 3). The best conversion (35\%) was observed from the reaction containing the mixture of C1-C4 with B1-B4. We divided again the carboxylate salts in two groups (C1-C2 and C3-C4) and the bases as well (B1-B2 and B3-B4); and four reactions were done combining each of them (step 4). $55 \%$ conversion was observed in the best scenario which after the last deconvolution step indicated that the most powerful catalytic systems consisted of $\left[\mathrm{RuCl}_{2}(p \text {-cymene) }]_{2}(5 \mathrm{~mol} \%), \mathrm{KOAc}(\mathbf{C 2}, 20 \mathrm{~mol} \%), \mathrm{K}_{2} \mathrm{CO}_{3}\right.$ (B2, 3 equivalents) and NMP as solvent. In this manner, a conversion of $75 \%$ was obtained with an isolated yield of $2 \mathbf{a}$ of $65 \%$ after purification by column chromatography. Consequently, efficient reaction conditions for such a challenging transformation were found with only 18 experiments in contrast with the 576 individual experiments that should have been conducted considering all the reagents employed individually. Additionally, we realized that the same reaction conditions applied to 4-iodopyridine as coupling partner were successful in a similar manner, however, when applied to 4chloropyridine the conversion significantly decreased to $<10 \%$. methylpyridine led to $\mathbf{2 d}$ in $78 \%$ yield. A single-crystal X-ray diffraction study unambiguously established the double heteroarylation at both ortho positions of the phenyl ring in $\mathbf{2 d}$. $^{[11]}$ Trifluoro-containing pyridine $2 \mathrm{e}$ was also obtained in a good yield (72\%). Dioxolane-containing $2 \mathbf{f}$ and piperidine-containing 2g were obtained in an excellent 91 and $88 \%$ yield, respectively; indicating that other heterocycles are also compatible with the ruthenium-catalyzed $\mathrm{C}-\mathrm{H}$ bond heteroarylation of triazoles. Decreasing by half the amounts of heteroaryl bromide and base $\left(\mathrm{K}_{2} \mathrm{CO}_{3}\right)$ led to the monofunctionalized products as the major ones. For example, 4pyridine- and 3-pyridine-containing triazoles $2 \mathbf{h}$ and $\mathbf{2 i}$ were obtained in 48 and $55 \%$ yield, respectively. The reaction was also compatible with ketone functional groups enabling the synthesis of $\mathbf{2 j}$ in $58 \%$ yield. 5-Bromopyrimidine reacted efficiently leading to mono-functionalized $\mathbf{2 k}$ in $63 \%$ yield. Mono-piperidine-containing triazole $2 \mathbf{l}$ was obtained in a similar yield $(65 \%)$. Trace amounts $(<5 \%)$ of bis-functionalized

products were observed for the synthesis of $\mathbf{2 h}, \mathbf{2} \mathbf{i}$ and $\mathbf{2 l}$; wher-

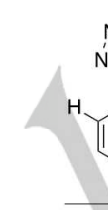

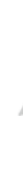

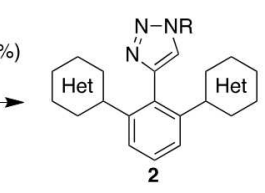

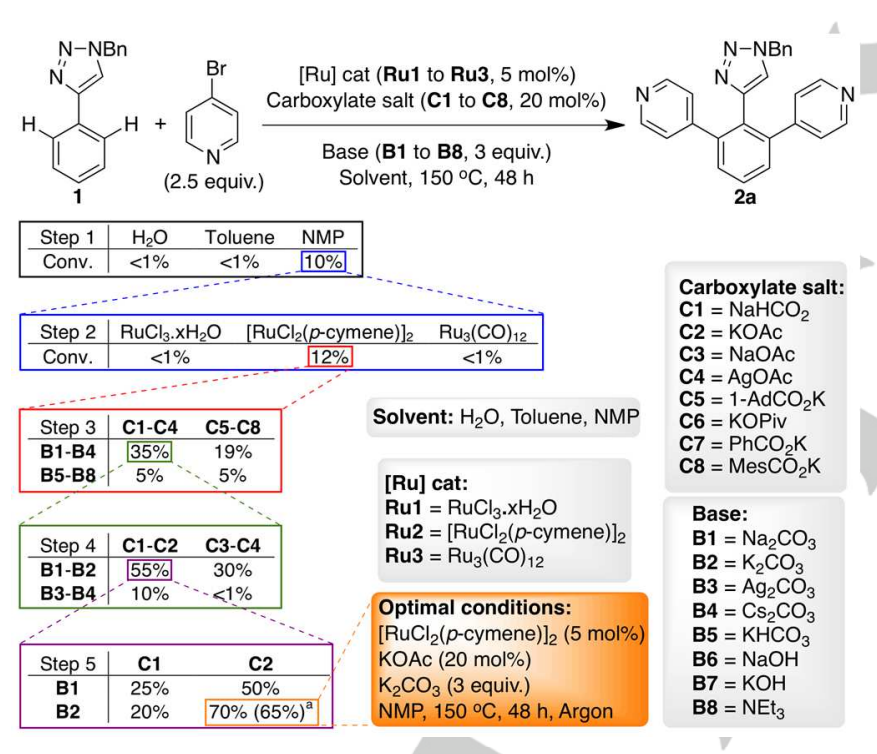

Figure 1. Deconvolution strategy for optimization of reaction conditions. [a] Isolated yield.

With the optimal reaction conditions in hand, we explored the scope of the reaction with different heteroaryl bromides (Scheme 2 ). In all the reactions an excess (2.5 equivalents) of heteroaryl bromide was used, leading to the bis-functionalized products as the major ones. For instance, 3-bromopyridine reacted with 1 in a similar manner as 4-bromopyridine leading to $\mathbf{2 b}$ in $71 \%$ yield. The bis-quinoline-containing triazole 2c was obtained in $68 \%$ yield, although its regioisomer 4-bromoisoquinoline did not react. Functionalized bromopyridines also reacted efficiently under the studied reaction conditions. For example, 2-bromo-62a, $65 \%$<smiles>c1cncc(-c2cccc(-c3cccnc3)c2-c2cn[nH]n2)c1</smiles>
2b, $71 \%$

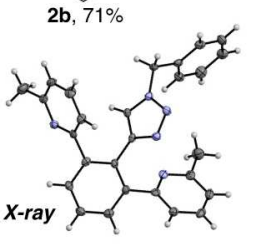
2c, $68 \%$<smiles>FC(F)(F)c1cccc(-c2c[14cH][14cH]cc2-c2cccc(C(F)(F)F)n2)n1</smiles>
2d, $78 \%$<smiles></smiles><smiles>c1ccc(-c2cc(-c3ccc(N4CCCCC4)cc3)c(-c3ccc(N4CCCCC4)cc3)c(-c3cnn[nH]3)c2)cc1</smiles><smiles>c1ccc(-c2cn(Cc3ccncc3)nn2)cc1</smiles>

2h, $48 \%^{a}$<smiles>O=C(O)c1cccc(-c2cn(Cc3ccccc3)nn2)c1-c1cccnc1</smiles><smiles></smiles>

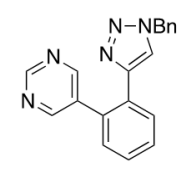

2k, $63 \%^{a}$

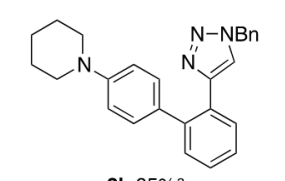

2I, $65 \% \mathrm{a}$

Reluctant substrates:

$$
\text { R= }
$$<smiles></smiles>
$2 \mathrm{~m}$

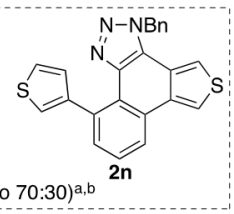

$\mathrm{MeO}_{2} \mathrm{C} \mathrm{C}^{\mathrm{Br}}$

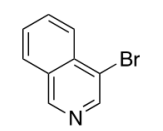

Scheme 2. Substrate scope and limitations. [a] Starting from 1.25 equivalents of heteroaryl bromide and 1.5 equivalents of $\mathrm{K}_{2} \mathrm{CO}_{3}$. [b] Starting from 3bromothiophene. 
-eas no bis-functionalization was detected during the formation of $2 \mathbf{j}$ and $\mathbf{2 k}$. 3-Bromothiophene reacted with an unexpected outcome leading to a mixture of products $\mathbf{2} \mathbf{m}$ and $\mathbf{2 n}$ in 70:30 ratio ( $75 \%$ combined yield). $2 \mathrm{~m}$ seems to be formed by an additional double $\mathrm{C}-\mathrm{H}$ bond functionalization between one $\mathrm{C}-\mathrm{H}$ bond belonging to the thiophene ring and the one belonging to the triazole ring. A similar oxidative coupling between a 1,2,3triazole ring and an intramolecular aryl ring using $\mathrm{Pd}(\mathrm{OAc})_{2}$ as a catalyst was previously reported, ${ }^{[7 c]}$ however the nature of the oxidant in the present case remains to be addressed. Unfortunately, we also noted that the reactions were not successful with 2-bromopyridine, aldehyde-, nitro-, chloro-, methoxy- and ester-containing bromopyridines (Scheme 2). ${ }^{[12]}$

Lastly, we decided to study whether it was possible to perform also $\mathrm{C}-\mathrm{H}$ bond arylation reactions of triazoles as it was done by Ackermann and co-workers with a different catalytic system also based on $\left[\mathrm{RuCl}_{2} \text { (p-cymene) }\right]_{2}$ (30 mol\% MesCO $\mathrm{CO}_{2} \mathrm{H}$ and $\mathrm{K}_{2} \mathrm{CO}_{3}$ as base in toluene). ${ }^{[7]} \mathrm{We}$ found that our abovedescribed protocol provides comparable results, and in some cases slightly outperforms the previous findings (Scheme 3 ). For example, methoxy-containing $3 \mathbf{3}$ was obtained in $85 \%$ yield. A single-crystal X-ray diffraction study of 3 a unambiguously confirmed that the bis-functionalization takes place at both ortho positions of the phenyl ring attached to the triazole core..$^{[11]}$ Nitrile groups (that were not studied before) at meta position were also tolerated with our protocol leading to bisfunctionalized $\mathbf{3 b}$ in $87 \%$ yield. Even bulky substrates such as 2-bromotoluene were found to react giving rise to bisfunctionalized $3 c$ in a decent yield (56\%). Reducing by half the amounts of coupling partner and base, we managed to obtain the mono-functionalized $\mathbf{3 d}$ and $\mathbf{3 e}$ as major products in 55 and $62 \%$ yield, respectively.

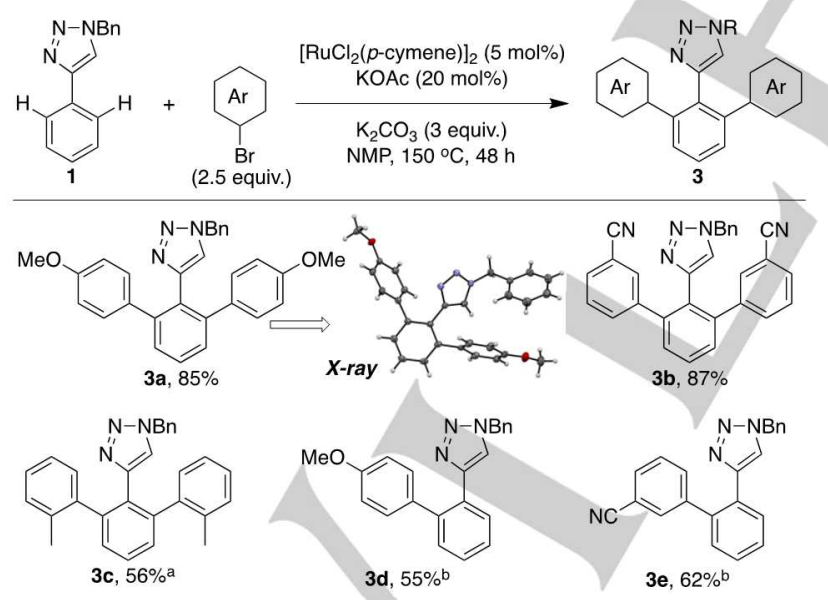

Scheme 3. Ruthenium-catalyzed $\mathrm{C}-\mathrm{H}$ bond arylation reactions of triazoles employing the optimal reaction conditions obtained by the deconvolution strategy. [a] Obtained as a mixture of atropoisomers. [b] Starting from 1.25 equivalents of heteroarylbromide and 1.5 equivalents of $\mathrm{K}_{2} \mathrm{CO}_{3}$

\section{Conclusions}

In summary, we have introduced a deconvolution strategy in ruthenium catalysis to efficiently search for suitable reaction conditions enabling a difficult $\mathrm{C}-\mathrm{H}$ bond heteroarylation reaction of 1,2,3-triazole fragments. In this way, a unique class of sterically crowded heterocycles, which are otherwise very difficult to synthesize by non-catalyzed sequences, has been obtained in good yields. The ruthenium-based catalytic system was found to be compatible with many relevant heteroaryl bromides such as pyridines, quinolines, dioxolanes, piperidines, pyrimidines and related substrates containing functional groups such as methyl, trifluoro, ketone or nitrile. It could be anticipated that by merging deconvolution strategies with transition metalcatalyzed $\mathrm{C}-\mathrm{H}$ bond functionalization reactions, new protocols could be found in the near future.

\section{Experimental Section}

Deconvolution experiments for step 1: Substrate $1(0.5 \mathrm{mmol}, 0.118 \mathrm{~g}$, 1 equiv.), 4-bromopyridine ( $1.25 \mathrm{mmol}, 2.5$ equiv.), all bases B1-B8 (1.5 mmol, 3 equiv.), all carboxylate salts $\mathbf{C} 1-\mathbf{C 8}(0.1 \mathrm{mmol}, 0.20$ equiv.), all ruthenium pre-catalysts Ru1-Ru3 $(0.025 \mathrm{mmol}, 0.05$ equiv.), and the corresponding solvent (water, toluene or NMP; $10 \mathrm{~mL}$-to improve solubility-) were introduced in a dry Schlenk tube under argon atmosphere. Each reaction mixture was stirred at $150^{\circ} \mathrm{C}$ for $48 \mathrm{~h}$. Then, each reaction mixture was cooled down to room temperature and dissolved in dichloromethane $(30 \mathrm{~mL})$. After filtration over celite and evaporation of the solvents under vacuum, each reaction mixture was analysed by ${ }^{1} \mathrm{H}$ NMR spectroscopy.

Deconvolution experiments for step 2: Substrate $1(0.5 \mathrm{mmol}, 0.118 \mathrm{~g}$, 1 equiv.), 4-bromopyridine (1.25 mmol, 2.5 equiv.), all bases B1-B8 (1.5 mmol, 3 equiv.), all carboxylate salts $\mathbf{C} 1-\mathbf{C} 8$ ( 0.1 mmol, 0.20 equiv.), the corresponding ruthenium pre-catalysts Ru1-Ru3 $(0.025 \mathrm{mmol}, 0.05$ equiv.), and NMP (10 mL -to improve solubility-) were introduced in a dry Schlenk tube under argon atmosphere. Each reaction mixture was stirred at $150^{\circ} \mathrm{C}$ for $48 \mathrm{~h}$. Then, each reaction mixture was cooled down to room temperature and dissolved in dichloromethane $(30 \mathrm{~mL})$. After filtration over celite and evaporation of the solvents under vacuum, each reaction mixture was analysed by ${ }^{1} \mathrm{H}$ NMR spectroscopy.

Deconvolution experiments for steps 3-5: Substrate $1(0.5 \mathrm{mmol}$, $0.118 \mathrm{~g}, 1$ equiv.), 4-bromopyridine (1.25 mmol, 2.5 equiv.), the corresponding bases B1-B8 (1.5 mmol, 3 equiv.), the corresponding carboxylate salts $\mathbf{C 1}-\mathbf{C} 8\left(0.1 \mathrm{mmol}, 0.20\right.$ equiv.), $\left[\operatorname{RuCl}_{2}(p \text {-cymene) }]_{2}\right.$ $(0.025 \mathrm{mmol}, 0.015 \mathrm{~g}, 0.05$ equiv.), and NMP $(2 \mathrm{~mL})$ were introduced in a dry Schlenk tube under argon atmosphere. Each reaction mixture was stirred at $150^{\circ} \mathrm{C}$ for $48 \mathrm{~h}$. Then, each reaction mixture was cooled down to room temperature and dissolved in dichloromethane $(30 \mathrm{~mL})$. After filtration over celite and evaporation of the solvents under vacuum, each reaction mixture was analysed by ${ }^{1} \mathrm{H}$ NMR spectroscopy.

General procedure for the Ru-catalyzed $\mathrm{C}-\mathrm{H}$ bond double heteroarylation of triazoles: Substrate $1(0.5 \mathrm{mmol}, 0.118 \mathrm{~g}, 1$ equiv.), the corresponding heteroaryl bomide ( $1.25 \mathrm{mmol}, 2.5$ equiv.), $\mathrm{K}_{2} \mathrm{CO}_{3}(1.5$ mmol, $0.207 \mathrm{~g}, 3$ equiv.), KOAc ( $0.1 \mathrm{mmol}, 0.098 \mathrm{~g}, 0.20$ equiv.), [RuCl 2 (p-cymene) ]2 ( $0.025 \mathrm{mmol}, 0.015 \mathrm{~g}, 0.05$ equiv.), and NMP (2 mL) were introduced in a dry Schlenk tube under argon atmosphere. The reaction mixture was stirred at $150^{\circ} \mathrm{C}$ for $48 \mathrm{~h}$. Then, the reaction mixture was cooled down to room temperature and dissolved in dichloromethane $(30 \mathrm{~mL})$. After filtration over celite and evaporation of the solvents under vacuum, the desired product (2) was purified by silica gel column 
chromatography with mixtures of heptane and ethyl acetate containing $1 \%$ of triethylamine.

\section{Acknowledgements}

CNRS, Université de Rennes 1, Rennes Métropole and COST Action CA15106 (C-H Activation in Organic Synthesis) are acknowledged for providing financial support. Dr. Arkaitz Correa is acknowledged for providing samples of compound $\mathbf{1}$.

Keywords: $\mathrm{C}-\mathrm{H}$ bonds $\cdot$ heterocycles $\cdot$ ruthenium • deconvolution screening $\bullet$ triazoles

[1] a) R. Huisgen, Angew. Chem. 1963, 75, 604-637; Angew. Chem. Int Ed. 1963, 2, 565-598; b) H. C. Kolb, M. G. Finn, K. B. Sharpless, Angew. Chem. 2001, 113, 2056-2075; Angew. Chem. Int. Ed. 2001, 40 2004-2021; c) C. W. Tornøe, C. Christensen, M. Meldal, J. Org. Chem. 2002, 67, 3057-3064; d) V. V. Rostovtsev, L. G. Green, V. V. Fokin, K. B. Sharpless, Angew. Chem. 2002, 114, 2708-2711; Angew. Chem. Int. Ed. 2002, 41, 2596-2599; e) M. Meldal, C. W. Tornøe, Chem. Rev. 2008, 108, 2952-3015; f) M. S. Singh, S. Chowdhury, S. Koley, Tetrahedron 2016, 72, 5257-5283.

[2] a) H. Nandivada, X. Jiang, J. Lahann, Adv. Mater. 2007, 19, 21972208; b) Y. L. Angell, K. Burgess, Chem. Soc. Rev. 2007, 36, 1674 1689; c) D. Fournier, R. Googenboom, U. S. Schubert, Chem. Soc. Rev 2007, 36, 1369-1380; e) J. E. Moses, A. D. Moorhouse, Chem. Soc. Rev. 2007, 36, 1249-1262; f) J.-F. Lutz, Angew. Chem. 2007, 119, 1036-1043; Angew. Chem. Int. Ed. 2007, 46, 1018-1025; g) A. Dondoni, Chem. Asian J. 2007, 2, 700-708; h) F. Amblard, J. H. Cho, R. F. Schinazi, Chem. Rev. 2009, 109, 4207-4220; i) R. K. Iha, K. L. Wooley, A. M. Nyström, D. J. Burke, M. J. Kade, C. J. Hawker, Chem. Rev 2009, 109, 5620-5686; h) A. Qin, J. W. Y. Lam, B. Z. Tam, Chem. Soc. Rev. 2010, 39, 2522-2544; i) H.-F. Chow, K.-N. Lau, Z. Ke, Y. Liang, C.-M. Lo, Chem. Soc. Rev. 2010, 46, 3437-3453; j) Y. Hua, A. H. Flood, Chem. Soc. Rev. 2010, 39, 1262-1271; k) A. H. El-Sagheer, T. Brown, Chem. Soc. Rev. 2010, 39, 1388-1405; I) K. D. Hänni, D. A. Leigh, Chem. Soc. Rev. 2010, 39, 1240-1251; m) C. O. Kappe, E. Van der Eycken, Chem. Soc. Rev. 2010, 39, 1280-1290.

[3] a) B. H. M. Kuijpers, G. C. T. Dijkmans, S. Goothuys, P. J. L. M. Quaedflieg, R. H. Blaauw, F. L. van Delft, F. P. J. T. Rutjes, Synlett 2005, 3059-3062; b) J. E. Hein, J. C. Tripp, L. B. Krasnova, K. B. Sharpless, V. V. Fokin, Angew. Chem. 2009, 121, 8162-8165; Angew. Chem. Int. Ed. 2009, 48, 8018-8021; c) C. Spiteri, J. E. Moses, Angew. Chem. 2010, 122, 33-36; Angew. Chem. Int. Ed. 2010, 49, 31-33; d) Y. Zhou, T. Lecourt, L. Micouin, Angew. Chem. 2010, 122, 2661-2664; Angew. Chem. Int. Ed. 2010, 49, 2607-2610; e) Y. Zhang, X. Li, J. Li, J. Chen, X. Meng, M. Zhao, B. Chen, Org. Lett. 2012, 14, 26-29; f) A. Goitia, E. Gómez-Bengoa, A. Correa, Org. Lett. 2017, 19, 962-965; g) G. Jiang, W. Hu, J. Li, C. Zhu, W. Wu, H. Jiang, Chem. Commun. 2018, 54, 1746-1749; h) L. Ackermann, H. K. Potukuchi, Org. Biomol. Chem. 2010, 8, 4503-4513.

[4] a) P. C. Chen, R. E. Wharton, P. A. Patel, A. K. Oyelere, Bioorg. Med. Chem. 2007, 15, 7288-7300; b) P. C. Chen, V. Patil, W. Guerrant, P. Green, A. K. Oyelere, Bioorg. Med. Chem. 2008, 16, 4839-4853; c) V. Patil, W. Guerrant, P. C. Chen, B. Gryder, D. B. Benicewicz, S. I. Khan, B. L. Tekwani, A. K. Oyelere, Bioorg. Med. Chem. 2010, 18, 415-425 d) C. Travelli, S. Aprile, R. Rahimian, A. A. Grolla, F. Rogati, M. Bertolotti, F. Malagnino, R. di Paola, D. Impellizzeri, R. Fusco, V. Mercalli, A. Massarotti, G. Stortini, S. Terrazzino, E. D. Grosso, G. Fakhfouri, M. P. Troiani, M. A. Alisi, G. Grosa, G. Sorba, P. L. Canonico, G. Orsomando, S. Cuzzocrea, A. A. Genazzani, U. Galli, J. Med. Chem. 2017, 60, 1768-1792.
[5] a) K. Ohmatsu, M. Kiyokawa, T. Ooi, J. Am. Chem. Soc. 2011, 133 1307-1309; b) K. Ohmatsu, Y. Hamajima, T. Ooi, J. Am. Chem. Soc. 2012, 134, 8794-8797; c) K. Ohmatsu, Y. Ando, T. Ooi, J. Am. Chem. Soc. 2013, 135, 18706-18709; d) K. Ohmatsu, Y. Furukawa, M. Kiyokawa, T. Ooi, Chem. Commun. 2017, 53, 13133-13116.

[6] a) Q. Tian, X. Chen, W. Liu, Z. Wang, S. Shi, C. Kuang, Org. Biomol. Chem. 2013, 11, 7830-7833; b) S. Shi, W. Liu, P. He, C. Kuang, Org. Biomol. Chem. 2014, 12, 3576-3580; c) S. Shi, C. Kuang, J. Org. Chem. 2014, 79, 6105-6112; d) Z. Wang, Q. Tian, X. Yu, C. Kuang, Adv. Synth. Catal. 2014, 356, 961-966; e) Z. Wang, C. Kuang, Adv. Synth. Catal. 2014, 356, 1549-1554; f) W. Liu, Y. Li, B. Xu, C. Kuang, Org. Lett. 2013, 15, 2342-2345; g) X. Yu, Z. Huang, W. Liu, S. Shi, C. Kuang, Org. Biomol. Chem. 2015, 13, 4459-4465; h) P. He, Q. Tian, C. Kuang, Org. Biomol. Chem. 2015, 13, 7146-7148; i) L. Ackermann, R. Vicente, R. Born, Adv. Synth. Catal. 2008, 350, 741-748; j) S. Chuprakov, N. Chernyak, A. S. Dudnik, V. Gevorgyan, Org. Lett. 2007, 9, 2333-2336; k) L. Ackermann, A. Althammer, S. Fenner, Angew. Chem. 2009, 121, 207-210; Angew. Chem. Int. Ed. 2009, 48, 201-204; I) L. Ackermann, H. Potukuchi, D. Landsberg, R. Vicente, Org. Lett. 2008, 10, 3081-3084; m) R. Jeyachandran, H. Poutukuchi, L. Ackermann, Beilstein J. Org. Chem. 2012, 8, 1771-1777; n) S. Zhao, R. Yu, W. Chen, M. Liu, H. Wu, Org. Lett. 2015, 17, 2828-2831; o) F. Zhao, Y. Liu, S. Yang, K. Xie, Y. Jiang, Org. Chem. Front. 2017, 4, 1112-1115.

[7] a) L. Ackermann, R. Vicente, A. Althammer, Org. Lett. 2008, 10, 22992302; b) L. Ackermann, R. Born, R. Vicente, ChemSusChem 2009, 2 , 546-549; c) L. Ackermann, R. Jeyachandran, H. K. Potukuchi, P. Novák, L. Büttner, Org. Lett. 2010, 12, 2056-2059; d) L. Ackermann, P. Novák, R. Vicente, V. Pirovano, H. K. Potukuchi, Synthesis 2010, 13, 22452253; e) C. Tirler, L. Ackermann, Tetrahedron 2015, 71, 4543-4551.

[8] a) X. G. Li, K. Liu, G. Zhou, P. N. Liu, Eur. J. Org. Chem. 2014, 78787888; b) A. Haito, M. Yamaguchi, N. Chatani, Asian J. Org. Chem. 2018, DOI: 10.1002 /ajoc.201800182.

[9] a) F. Kakiuchi, N. Chatani, Adv. Synth. Catal. 2013, 345, 1077-1101; b) K. Godula, D. Sames, Science 2006, 312, 67-72; c) L. McMurray, F. O'Hara, M. J. Gaunt, Chem. Soc. Rev. 2011, 40, 1885-1898; d) D. A Colby, A. S. Tsai, R. G. Bergman, J. A. Ellman, Acc. Chem. Res. 2012, 45, 814-825; e) P. A. Arockiam, C. Bruneau, P. H. Dixneuf, Chem. Rev. 2012, 112, 5879-5918; f) J. Yamaguchi, A. D. Yamaguchi, K. Itami, Angew. Chem. 2012, 124, 9092-9142; Angew. Chem. Int. Ed. 2012, 51 8960-9009; g) L. Ping, D. S. Chung, J. Bouffard, S.-G. Lee, Chem. Soc. Rev. 2017, 46, 4299-4328; h) C-H Activation (Eds.: J.-Q. Yu, Z. Shi) Springer, Berlin, 2010; i) $\mathrm{C}-\mathrm{H}$ Bond Activation and Catalytic Functionalization I and II (Eds.: P. H. Dixneuf, H. Doucet), Springer, Switzerland, 2016; j) Asymmetric Functionalization of C-H Bonds (Ed.: S.-L. You), RSC, Cambridge, 2015; k) $C-H$ and $C-X$ Bond Functionalization: Transition Metal Mediation (Ed.: X. Ribas), RSC, Cambridge, 2013; I) L. Ackermann, R. Vicente, H. K. Potukuchi, V. Pirovano, Org. Lett. 2010, 12, 5032-5035; m) F. Yang, L. Ackermann, J. Org. Chem. 2014, 79, 12070-12082.

[10] a) M. T. Reetz, T. Sell, A. Meiswinkel, G. Mehler, Angew. Chem. 115, 814-817; Angew. Chem. Int. Ed. 2003, 42, 790-793; b) J. Wieland, B. Breit, Nature Chem. 2010, 2, 832-837; c) P. Dydio, C. Rubay, T. Gadzikwa, M. Lutz, J. N. H. Reek, J. Am. Chem. Soc. 2011, 133, 17176-17179; d) K. Ohmatsu, Y. Hara, T. Ooi, Chem. Sci. 2014, 5, 3645-3650; e) K. D. Collins, T. Gensch, F. Glorius, Nature Chem. 2014, 6, 859-871; f) E. Wolf, E. Richmond, J. Moran, Chem. Sci. 2015, 6, 2501-2505; g) K. Troshin, J. F. Hartwig, Science 2017, 357, 175-181.

[11] CCDC 1846484 (for 2d) and 1846485 (for 3a) contain the supplementary crystallographic data for this paper. These data can be obtained free of charge from The Cambridge Crystallographic Data Centre.

[12] For examples of absence of reactivity of aryl bromides containing aldehyde and nitro functional groups in ruthenium-catalyzed $\mathrm{C}-\mathrm{H}$ bond functionalization, see: a) C. Bruneau, R. Gramage-Doria, Adv. Synth. Catal. 2016, 358, 3847-3856; b) R. Gramage-Doria, S. Achelle, C. 
Entry for the Table of Contents (Please choose one layout)

\section{COMMUNICATION}

The application of a deconvolution strategy to ruthenium catalyzed $\mathrm{C}-\mathrm{H}$ bond functionalization provided appropriate reaction conditions to perform the unprecedented heteroarylation of triazole scaffolds in good yields. This was possible after screening 22 parameters ( 3 solvents, 3 ruthenium complexes as precatalysts, 8 carboxylate salts as cocatalysts and 8 bases) in only 18 designed experiments.

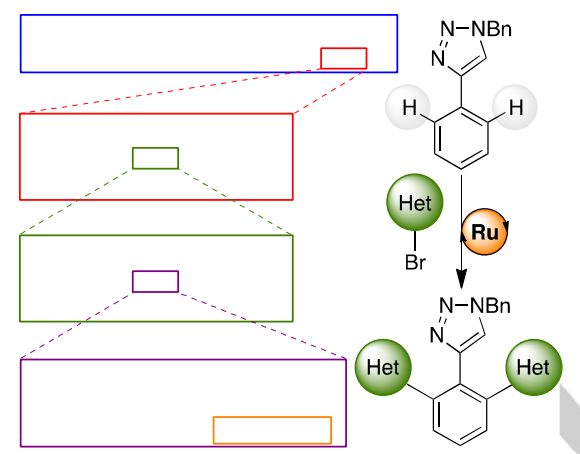

\section{Triazoles}

Rafael Gramage-Doria, * Thierry Roisnel

Page No. - Page No.

Ruthenium-Catalyzed C-H Bond

Heteroarylation of Triazoles Enabled by a Deconvolution Strategy 